\title{
Kutadgu Bilig'de “iyi olan yukarıda, kötü olan aşağıda metaforu” üzerine
}

\section{Melike Sultan ÖZEVREN1}

\begin{abstract}
APA: Özevren, M. S. (2019). Kutadgu Bilig'de "iyi olan yukarıda, kötü olan aşağıda metaforu" üzerine. RumeliDE Dil ve Edebiyat Araşttrmalar Dergisi, (Ö5), 69-76. DOI: 10.29000/rumelide.606070.
\end{abstract}

\section{$\ddot{\mathbf{O} z}$}

İslâmi Türk edebiyatının bilinen ilk büyük eseri olan Kutadgu Bilig zengin bir söz varlığına sahiptir. Bu söz varlığındaki mevcut metaforlar döneminin kavram dünyasını yansıtır. Yansıttı̆̆ı kavramların temelinde de toplumun tecrübeleri, kültürel birikimi, hayata bakış açısı ve zihnin dünyayı nasıl algıladı̆̆ı yer alır. Metaforlar, günlük hayatımızda dünyanın nasıl algılanıp kavramlaştırıldı̆̆ını ifade

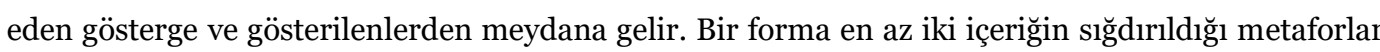
düşünce sistemimizin doğal bir parçasıdır. Düşünceleri somutlaştırır ve nesnelleştirir, bu da dilimizin etkili ve ustaca işlenebilirliğini gösterir. Her alanda kullanılan metaforlar edebiyatta da kullanılmıştır. Çalışmamızda, Kutadgu Bilig'de yer alan yönelim metaforları incelenmiştir ve otuz sekiz adet yönelim metaforu tespit edilmiştir. Tespit edilen metaforlar günümüzde de devamlılı arz eder. Bu devamlılık bize kültür ile metaforun doğrudan ilişkili olduğunu gösterir.

Anahtar kelimeler: Kutadgu Bilig, metafor, yönelim metaforları.

\section{"The good above, the bad below metaphor" in Kutadgu Bilig}

\begin{abstract}
Kutadgu Bilig, the first known great work of Islamic Turkish literature, has a rich vocabulary. In this fortune, the present metaphors reflect the concept world of the era. On the basis of the concepts it reflects are the experiences of the society, cultural accumulation, perspective of life and how the mind perceives the world. The metaphor consists of the indicators and the ones that express how the world is perceived and conceptualized in our daily lives. Metaphors in which at least two contents fit into one form are a natural part of our thinking system. It embodies and objectifies thoughts, which shows the effective and ingenious processability of our language. Metaphors used in every field have also been used in literature. In our study, orientation metaphors in Kutadgu Bilig were examined and thirty-eight orientation metaphors were identified. The metaphors identified are still continuous today. This continuity shows us that the metaphor is directly related to culture.
\end{abstract}

Keywords: Kutadgu Bilig, metaphor, orientation metaphors.

\section{Giriş}

Bilindiği üzere Türk edebiyatına gerçek bir çığır açan eserlerden biri olarak Kutadgu Bilig, 1069-1070 yılları arasında Yusuf Has Hâcib tarafından döneminin standart dili, Hakaniye Türkçesi ile kaleme alınmıştır. İslâmi Türk edebiyatının bilinen ilk büyük eserinde sanat gayesi güdülmemiş olmasına rağmen, eserde edebî zevk oldukça yüksektir ve dil kusursuz bir şekilde işlenmiştir. Kutadgu Bilig'de at

$1 \quad$ Dr. Öğrencisi, Trakya Üniversitesi, Sosyal Bilimler Enstitüsü, Türk Dili ve Edebiyatı ABD, Türk Dili BD (Edirne/ Türkiye), melikeozevren@gmail.com, ORCID ID: 0ooo-0001-9535-5485 [Makale kaylt tarihi: 25.04.2019-kabul tarihi:18.08.2019; DOI: $10.29000 /$ rumelide.606070] 
kültü, büyüklerin küçüklere "kuzu" şeklinde hitap etmesi gibi Türk folklor motifleri, büyüklerin küçüklere öğütleri, döneminin ideal toplum ve yönetimi hakkında bilgi edinmek mümkündür.

Kutadgu Bilig, zengin bir söz varllğına sahiptir. Kutadgu Bilig'in 3 bin kelimeye yakın söz servetinin yanı sıra, belki onun iki üç misli kadar zengin kelime grubu ve kavram ihtiva ettiğini, ayrıca kelimeler dünyasının sıklık sayılarından hareketle kısmen de olsa, bu Türk klasiğinin ifade kudretini anlamak ve göstermek gerekmektedir (Ergüzel \& Kirik, 2018, s. 385).

Kutadgu Bilig, akli melekeleri yerinde olanlara her iki cihan saadetine kavuşmak için yol gösteren bir eserdir. Kutadgu Bilig”in ana temi "ideal insan"dır (Ercilasun, 2016, s. 304).

\begin{abstract}
Yusuf Has Hâcib’in ideal insanı, "bütün kötü vasıflarından arınmıș ve iyi huylarla bezenmiş bir insandır. Allah'a sıkı sskıya bağlı, takva sahibi bir mü’mindir. Zamanının bütün ilim ve hünerlerini öğrenmiş bir âlim ve hakimdir. Bütün alfabeleri ve dilleri bildiği gibi șiir, belâgat, hesap, hendese, tıp, he'yet vb. ilimlere vâkıf; okçuluk, avcılık, satranç vb. hünerlere sahiptir. Adaletten ve doğruluktan şaşmaz; ağırbaşlı ve alçak gönüllüdür. Hırsızlık yapmaz, yalan söylemez, içki içmez, dedikodu etmez. Son derece cömert ve iyilikseverdir. Etrafindaki insanlara merhametli ve insaflı davranır. Âdet ve an'anelere, görgü kurallarına uygun hareket eder." (Ercilasun, 1985, s. 132-133).
\end{abstract}

Biz de çalışmamızda iyi olan yukarıda, kötü olan aşağıda şeklinde yaptığımız ayrımı Yusuf Has Hâcib’in ideal insan görüşü ve kendi duygu değerlerimiz doğrultusunda inceledik.

\title{
Metafor
}

Metafor kavramı modern anlamda hayatımıza 20. yüzyldda, 1980'de, George Lakoff ve Mark Johnson'ın kaleme almış olduğu Metaphors We with Live by adlı eser ile girmiştir.

Bizde ise bu eserden önce de farklı bir kavram ile hayatımızdaki varlı̆̆ını sürdürmekteydi. Metafor kavramı günümüze kadar farklı şekilde adlandırılmış ve anlamlandırılmıştır. Şemsettin Sami'nin Kâmûs-ı Türkîssinde istiâre adıyla "ödünç alma, âriyet olarak kullanma" (Sami, 2007, s. 101), Muallim Naci'nin Lûgat-i Nacî’sinde istiâre adıyla “âriyet olarak almak” (Nâci, 2006, s. 61), Ferit Devellioğlu'nun lugatında istiâre adıyla "ödünç alma, bir kelimenin mânâsını muvakkaten başka bir kelime hakkında kullanma” (Devellioğlu, 2012, s. 521), TDK'nin Türkçe Sözlük'ünde metafor adıyla “mecaz" (Türkçe Sözlük, 2011), Günay Karaağaç’ın Dil Bilimi Terimleri Sözlüğü’nde metafor maddesi bulunmasına rağmen iğretileme maddesine yönlendirerek "bir varlığın bir başka varlığın göstereni olması durumudur. Gösteren olmak, kendisi dışında bir başka varlığa işaret etmektir...” (Karaağaç, Dil Bilimi Terimleri Sözlüğü, 2013, s. 466) şeklinde anlamlandırılmıştır. Doğan Aksan'ın Anlambilim’inde ise deyim aktarması ya da iğretileme olarak adlandırılmıştır (Aksan, 2017, s. 79).

Dilin kavram dünyasında olan bir şey ile başka bir şeyin anlatılabilmesi dilin işlenmişliğinin göstergesidir. Bu işlenmişliğin alametlerinden biri de metafordur. Metafor, bir forma en az iki içeriğin sığdırılmasıdır (Lakoff \& Johnson, 2015, s. 10). Metaforun gerçekleşebilmesi için kaynak alana dair bilgiler hedef alana aktarılır. Kavramların çeşitli yönleriyle birlikte başka kavramlarla benzerlik ilişkisi kurulması sonucu şekillenen metaforlar, toplumun özellikle soyut nitelik arz eden kavramlara nasıl yaklaştı̆̆ını ortaya koyması açısından bizlere ışık tutmaktadır. Dildeki mecazlı yapılarda somut olarak kendini gösteren kavramsal metaforlar, dilsel ögelerin doğuşunu anlamamıza da katkıda bulunmaktadır (Çetinkaya, 2017, s. 380). 
Geçmişten günümüze neredeyse her alanda kullanılan metaforlar hem dille hem de zihnin dünyayı nasıl algıladığıyla alakalıdır. İki şey arasındaki benzerlikler ve farklılıklar dahilinde bir şey ile başka bir şey yer değiştirir, bu da alıcıyı yeni ve farklı bir düşünce boyutuna sürükler.

Dil sadece bir "göstergeler imparatorluğu" değil, aynı zamanda bir "metaforlar imparatorluğu"dur da. Konuşan daima dildir ve dilin dili, metafordur (Lakoff \& Johnson, 2015, s. 9-10). İnsanoğlunun dünyayı anlama ve algılama yolunda icat ettiği metaforlar ait olduğu kültürün, toplumun ve dil birliğinin kodlarını taşır.

Dilin doğal unsuru olan metaforlara günlük hayatımızda sıkça rastlamak mümkündür. En basit örneğiyle hemen herkesin kullandığı "Vakit nakittir." cümlesini ele alabiliriz. Bu iki kavramın çeşitli benzerliklerinden yola çıarak; vakit, para gibi harcanabilir, tükenebilir, tüketilebilir, kazanılabilir, kaybedilebilir, tasarruf edilebilir, israf edilebilir vs. daha nice örnekler verilebilir.

George Lakoff ve Mark Johnson Metaforlar adlı ortak eserinde kaynak kavram alanı ile hedef kavram alanı arasındaki ilişkiler neticesinde metaforları yönelim metaforları, ontolojik ve yapısal metaforlar olarak üçe ayırır. Konumsal metaforlar diye de adlandırılan yönelim metaforları; yukarı-aşağı, ön-arka, içeri-dışarı, derin-sı̆̆, ileri-geri şeklinde karşımıza çıkar. Ontolojik metaforlar fiziksel nesnelerle olan tecrübelerimiz sonucunda ortaya çıkar (Örn: zihin bir makinedir, enstrüman arkadaştır,kitap dosttur). Yapısal metaforlar ise bir kavram alanını başka bir kavram alanı ile yapılandırır (Örn: hayat bir yolculuktur, zaman hareket eden bir nesnedir). İnsanoğlunun yeryüzündeki konumundan ve tecrübelerinden hareketle oluşturulan yukarı/aşağı, içeri/dışarı, ön/arka, beri/öte, derin/satıh, merkez/çevre gibi uzay/mekân yönelimleri kavramlara yön verir (Sarı, 2016, s. 213).

Dikey doğrultuda yönelimlere dayanan bu metaforlar, iyi/değerli olanın yukarıda olduğu veya yukarıya doğru hareket ettiği; kötü/değersiz olanın aşağıda olduğu veya aşağıya doğru hareket ettiği esasına dayanır. İnanç sistemimizde, yöneten-yönetilen ilişkisinde yukarı kavramının daha değerli, üstün bir niteliğe sahip olduğu bilinmektedir. İnsanın yaşadığı tecrübeler, iyi, güzel, değerli olanı yukarıda düşünmesine; yukarıya doğru olan hareketi iyi, güzel, değerli hareketler şeklinde değerlendirmesine sebep olmuştur (Çetinkaya, 2017, s. 387).

\section{Kutadgu Bilig'de “iyi olan yukarıda, kötü olan aşağıda metaforu”}

Dil, sözlü ve yazılı olarak iletişimde kullandığımız, doğduğumuzda hazır bularak edinmeye başladığımız, doğrudan doğruya insana özgü, çok güçlü, büyülü bir düzendir; düşünme ve düşünüleni aktarma dizgesidir (Aksan, 2017, s. 17). Dil, yalnızca düşünceyi aktaran, ileten bir dizge değil, aynı zamanda onu oluşturan, biçimlendiren bir dizgedir (Aksan, 2017, s. 19). Dilin biçimlendirme dizgesi görevini de üstlenmesi bizi bu çalışmada metafora yönlendirmiştir. Anlatılmak istenileni kolaylaştırarak aktaran metaforları Kutadgu Bilig'de Yusuf Has Hâcib’in ideal insan görüşü ve kendi duygu değerlerimiz doğrultusunda inceledik. Bu incelemede Reşit Rahmeti Arat'ın Kutadgu Bilig I Metin (Arat, Kutadgu Bilig I Metin, 1991) ve Kutadgu Bilig (Arat, 2008) adlı eserlerinden istifade ettik.

Evrensel nitelikteki konumsal metaforlardan iyi olan yukarıdadır / kötü olan aşağıdadır'da toplum zihninde iyi olan, bir değere sahip olanın yukarıda bulunduğu veya yukarı yönlü hareket ettiği; kötü, değersiz nitelikte olanın ise aşağıda bulunduğu veya aşağı yönlü hareket ettiği düşüncesinin var olduğunu görmekteyiz. Türkçedeki "havalara uçmak, başı göğe ermek; yerin dibine girmek" deyimlerini bu konumsal metaforlara örnek olarak verebiliriz (Çetinkaya, 2017, s. 383).

Yine Türkçedeki ayakları yerden kesilmek, baş tacı etmek, altından kalkmak, el üstünde tutmak, ayağını altına almak, gölge düşürmek, gözden düşmek, yerin dibine girmek, başı dara düşmek, 
"The good above, the bad below metaphor" in Kutadgu Bilig / M. S. Özevren (p. 69-76)

ocağına düşmek, küçük düşmek, elden ayaktan düşmek, adı batmak gibi deyimlerini de örnek olarak vermek mümkündür.

Çalışmamızda da bilgili olan, görevini yerine getiren, değerli, sabırlı, vefalı, alçakgönüllü, erdemli, başkalarına faydalı, akla, yüreğe, töreye ve usule vakıf olan, babasının hayır duasını alan, beyinin iyi sözlerine mazhar olan, varlığı (akıl ve bilgi) bulan, büyüklere saygı ve hürmette bulunan, dünyayı bırakıp vazgeçen, insanlık yolunu tutan ve doğru yolda olup doğru hareket eden yukarıdadır. Tespit edilen "iyi olan yukarıdadır" metaforunun bulunduğu beyitler şunlardır:

KB/220 k kayu öḍte erse bu künde burun

biligligke tegdi beḍükrek orun

"Hangi çağda olursa olsun, bugüne kadar/daha yüksek yer dâima bilgiliye kısmet olmuştur."

KB/356 basa aydım emdi kör ögdülmişig

uḳuş atı ol bu beḍüür kişig

"Bundan sonra Ögdülmiş’i anlattım;/o aklın adıdır ve kişiyi yükseltir."

KB/610 tapug arturu bardı künde yangı

aġırladı ilig küninge öngi

"O günden güne hizmetini arttırmakta/hükümdar da onu günden güne yükseltmekteydi."

$\mathrm{KB} / 611$ tapug birle begler aġırlar ḳulug

tapug singse boldı kiçig öz ulug

"Beyler kulu hizmetleri yüzünden yükseltir,/ hizmetleri beğenildikçe küçükler yükselir."

$\mathrm{KB} / 614$ tegimsiz tapug birle törke tegir

yarağsız yaransa kör ilke tegir

“ikkbale erişemeyen insan hizmeti sayesinde başköşeye geçer;/liyâkatsiz kişi yaranmaya çalışsa da kapı eşiğini boylar."

$\mathrm{KB} / 617^{2} \quad$ küninge örü bardı içrek bolu

ḳoḳuz boldı ḳaḍgu sewinçi tolu

"Hükümdara günden güne daha fazla yaklaşarak yükselmeye devam etti;/kaygısı gittikçe azaldı, sevinci gittikçe arttı."

KB/902 ḳayu neng uçuz bolsa yirde yatur

ağı çuz aġır boldı törde yatur

"Hangi şey değersizse ona kimse bakmaz bile; ipekli ve ağır/Çin kumaşları, değerli olduğu için başköşede yer alır."

KB/1322 seringil serinmek eren ḳılḳı ol

serinse bulur er mesel kökke yol

"Sabırlı ol, sabretmek er kişi işidir;/sabrederse, göğe bile yer bulur."

KB/1691 vefaḳa vefa ol kişilik hạaḳı

vefa ḳıl kişi bol atıngnı beḍüt

"Vefaya karşı vefa göstermek insanlık görevidir;/vefakarlık et, insan ol ve adını yükselt."

KB/1692 küninge aġırladı ilig anı

ḳamug ilke toldı kör atı üni

${ }^{2}$ Eserde hükümdara yaklaşmak hizmette kusur etmemekle alakalıdır. 
"Hükümdar onu günden güne yükseltti:/adı ve şöhreti bütün ülkeye yayıldı."

KB/1693 buḍunda beḍük boldı belgü nişan ajunda çawı bardı edgü du'an

"Derecesi ve mevkisi halk arasında yükseldi;/hayr dualar aldı, şöhreti dünyaya yayıldı."

$\mathrm{KB} / 1694$ ulug boldı iş tuş ara belgülüg beḍ̈k boldı begler ara bu külüg

"Eşi ve akranı arasında yükselmiş olduğu gibi,/şöhretiyle beyler arasında da büyüklerden oldu."

KB/1803 atam ḳıldı erdi kör eḍgü du'a

du'a birle tegdim bu yirke aga

"Babam bana hayır dua etmişti;/ben o duayla yükselerek bu mevkiye ulaştım."

$\mathrm{KB} / 2120 \quad$ küwezlik asıġsız köngül tumlıtur köngül ḳoḍ̣ıı bolsa kişig yoḳlatur

"Gurur faydasızdır o gönülleri kendinden soğutur;/kişiyi alçakgönüllülük yükseltir."

KB/2452 biligsiz kişi ol ḳurug sır beḍiz biliglig kişi ornı kökte eḍiz

"Bilgisiz adam boş bir kalıptan ibarettir;/bilgili kimsenin yeri gökten daha yüksektir."

$\mathrm{KB} / 2643$ yalawaç bilir bolsa erdem ḳamug beḍüyür begi atı ilde ulug

"Elçi her türlü erdeme sahip olursa,/beyi büyür ve adı o memlekette yükselir."

$\mathrm{KB} / 2646$ kişi erdemi birle erdin keçer öküş bolsa erdem er örlep uçar

"Kişi başkalarına erdemiyle üstün olur;/kimin erdemi çoksa o uçar gibi yükselir."

$\mathrm{KB} / 3369$ kişike tusulgu kerek bu tirig tirig tutsa atın kopursa erig

"İnsan hayatında kendini yükseltmek ve adını/yaşatmak için başkalarına faydalı olmalı."

$\mathrm{KB} / 3981$ bu neng birle yalnguk tilese tilek yaşıl kökke yoḳlar neng ol keḍ yölek

“İnsan arzu ederse, bu varlık sayesinde mavi göğe yükselir;/servet çok önemli bir destektir."

$\mathrm{KB} / 4015^{3}$ anın ötrü begler beḍütür küçin yaġı boynı yençer alır öz öçin

"Beyler kudretlerini bunlarla yükseltir;/düşmanlarının başını ezer ve öçlerini alırlar."

$\mathrm{KB} / 4304$ ulugigg aġıla küḍez ḥurmeti ulugiluḳ sanga kelgey yukggay ḳutı

"Büyüklere saygı göster, hürmette kusur etme;/böylece sen de yükselirsin, onların mutluluğu sana da bulaşır."

\footnotetext{
3 Bu beyiti 4013-4014. beyitlerle olan bağlamda düşünmek gerekir.

$\mathrm{KB} / 4013 \quad$ ajun tutg்çc er ukuşlug kerek budun basģuçıka kerek ked yürek

"Dünyayı tutan insan akıllı olmalı;/halkın başında bulunan da yürekli olmalı."

$\mathrm{KB} / 4014 \quad$ bu iki bolunsa basa tapuġçı törülüg tokulug kerek bilgüçi
}

"Bu ikisinden sonra, hizmetkârlar da/töre ve usule vâkıf olmalı." 
"The good above, the bad below metaphor" in Kutadgu Bilig / M. S. Özevren (p. 69-76)

KB/5420 beḍük tut bu himmet eḍiz tut köngül

ḳoḍu bir bu dünya munıngdın töngül

"Himmeti büyük ve gönlü yüksek tut;/bu dünyayı bırak, ondan vazgeç."

$\mathrm{KB} / 5593$ tusulur tenginçe aġırla açın

bayutg்ll nengin sen beḍütgil küçin

"Faydalı oldukları oranda onlara izzet, ikram ve/ihsanda bulun; gelirlerini artır, rütbelerini yükselt."

$\mathrm{KB} / 5729$ negü tir eşitgil tusulur kişi

tusulur kişi ol kişide başı

"Başkalarına faydalı olan kişi ne der, dinle;/başkalarına faydalı olan insan insanların başıdır."

KB/5788 kişilik ḳıl ay er kişi bol ulug

kişi mundağ urdı kişilik yolut

"Ey mert insan, insan ol ve bu vasfınla yüksel;/insan insanlık yolunu böyle tarif etti."

KB/5789 kişi bol kişike kişilik ḳılın

kişi atı ögdi özüngke alın

“İnsan ol, insanlara karşı insanlık yap;/insan vasfını kendin için en yüksek unvan olarak taşı."

$\mathrm{KB} / 5892$ kişi eḍgüsi kim kişiler başı

kişilik ḳılığlı kişike tuşı

"İnsanların iyisi ve insanların başı,/başkalarına karşı daima insanca davranan kişidir."

KB/6611 bilig bil kişi bol beḍütgil özüng

ya yılḳı atanğıl kişide yıra

"Sen ya bilgi bil, insan ol ve kendini yükselt/ya da hayvan adını al ve insanlardan uzaklaş."

KB/6641 yolung tüzgil emdi yorıḳıng köni

özüng iki ajunda bulg̈ll töre

"Şimdi yolunu düzelt, doğru hareket et,/her iki dünyada da başköşeye geç."

Bilgisiz, akılsız, boğazlarının esiri, düşmansız4 olan, azmış, dünyaya gönül veren, harama el uzatan, haram yiyen ve Rabbinden kaçıp isyan eden aşağıdadır. Tespit edilen "kötü olan aşağıdadır" metaforunun bulunduğu beyitler şunlardır:

KB/298 körü barsa yaḳşı ayur bu sözüg

uḳuşsuz biligsiz beḍütmez özüg

“Dikkat edersen şu söz çok yerinde söylenmiş:/akılsız ve bilgisiz kişi kendini yükseltemez.”

$\mathrm{KB} / 614$ tegimsiz tapug birle törke tegir

yarağsız yaransa kör ilke tegir

"İkbale erişemeyen insan hizmeti sayesinde başköşeye geçer;/liyakatsiz kişi yaranmaya çalışsa da kapı eşiğini boylar.

KB/3089 aya yolda azmış başı tezginük

ayı sewme dünyag tüpi ol üyük

“Ey yoldan azmış, başı dönmüş kişi,/bu dünyaya gönül verme, onun dibi bataklıktır.”

KB/3090 üyükke kirigli üyüldi ḳoḍı

${ }^{4}$ Kutadgu Bilig’in 3417. beyitinde geçen yavuzḳa yag̉ı yok “kötünün düşmanı yoktur” cümlesine dayalı olarak alınmıştır. 
örü kelmedi ol sewinç bulmadı

"Bataklığa giren dibe batar, kimse oradan bir daha/çıkamaz; orada sevinç arama."

$\mathrm{KB} / 3419^{5} \quad$ yağı birle tegşip er atı beḍür

yağısız kişi atı ḳopmaz yatur

“İnsanın adı düşmanla çarpışa çarpışa büyür;/düşmansız kişinin adı yükselmez, yerde kalır.”

KB/4592 telim baynı kördüm bog̀uz bulnadı

özi boldı müflis çıgaylık yidi

"Birçok zengin gördüm boğazlarının esiri oldular,/böylece iflas ederek tekrar yoksulluğa düştüler.”

$\mathrm{KB} / 4754 \quad$ yarasa tapug özke erksiz bolur

yaramasa tapğı küninge ilür

"Hizmeti beğenilirse, o kendisine hâkim olamaz;/hizmeti beğenilmezse, günden güne itibardan düşer.”

KB/5261 harâmḳa ḳatılma küḍez öz katı̀g, ḥarâm yigli ornı tamu ol batı̀g

"Harama el uzatma, kendini iyice gözet;/haram yiyenin yeri cehennemin dibidir.”

KB/5710 kürek men iḍimdin küremiş otun ḳamug öz yazuḳḳa kömüldi bütün

“Ben bir kaçă̆ım, rabbimden kaçmış bir asiyim;/bütün varlığım boyunca günaha batmıştır.”

\section{Sonuc}

Kerim Demirci’nin de dediği gibi "sözlükte durduğu gibi durmayan kelimeler" kendisini bu çalışmada farklı bir kavram alanında göstermiştir. Dilin imkanlarını sınırsız hale getiren metaforlar toplumsal bir süzgeçten geçerek alışılmış kelimelere yeni manalar kazandırmıştır. Döneminin kavram dünyası, bu kavram dünyasına olan bakış açısı, toplumun kültürel birikimi ve sosyal gerçeklikler metaforlar aracılı̆̆ıyla yansıtılmıştır. Çalışmamızda bilgili olan (2), görevini yerine getiren (4), değerli (1), sabırlı (1), vefalı (4), alçakgönüllü (1), erdemli (2), başkalarına faydalı (2), akıl, yürek, töre ve usule vakıf olan (1), babasının hayır duasını alan (1), beyinin övgüsüne mazhar olan (1), varlığı (akıl ve bilgi) bulan (3), büyüklere saygı ve hürmette bulunan (1), dünyayı bırakıp vazgeçen (1), insanlık yolunu tutan (4) ve doğru yolda olup doğru hareket eden (1) yukarıda; bilgisiz, akılsız (1), boğazlarının esiri (1), düşmansız olan (1), azmış ve dünyaya gönlünü veren (2), harama el uzatan, haram yiyen (1) ve rabbinden kaçıp isyan eden (1) aşağıdadır. Çalışmada yer alan metaforlarda yirmi dokuzu yukarıda, dokuzu aşağıda olan toplamda otuz sekiz adet yönelim/konumsal metaforu tespit edilmiştir. Bunlardan 614. beyitte tespit edilen metafor hem iyi olan yukarıda hem de kötü olan aşağıda metaforuyla birlikte iki kez sunulmuştur.

Tespit edilen yönelim metaforlarının, günümüzdeki yönelim metaforları ile olan benzerliği kültürümüzün devamlılığının bir göstergesidir. Türk toplumunun dış dünyayı nasıl anlayıp algıladığını ortaya koymak için diğer tarihî dönemlerde kaleme alınmış eserlerin de incelenmesi gerekir.

\section{Kaynakça}

Aksan, D. (2017). Anlambilim Konuları ve Türkçenin Anlambilimi. Bilgi.

Arat, R. R. (2008). Kutadgu Bilig. İstanbul: Kabalcı.

5 Kutadgu Bilig'in 3417. beyitinde geçen yavuzḳa yag̉ı yok “kötünün düşmanı yoktur” cümlesine dayalı olarak alınmıştır. 
Arat, R. R. (1991). Kutadgu Bilig I Metin. Ankara: Atatürk Kültür, Dil veTarih Yüksek Kurumu Türk Dil Kurumu.

Çetinkaya, B. (2017). Kutadgu Bilig'de Kavramsal Metaforlar. Afyon Kocatepe Üniversitesi Sosyal Bilimler Dergisi , 19 (2), 377-399.

Demirci, K. (2017). Türkoloji Öğrencileri İçin Dilbilim Konular Kavramlar Teoriler. Ankara: Anı.

Devellioğlu, F. (2012). Osmanlıca - Türkçe Ansiklopedik Lugat. Ankara: Aydın Kitabevi.

Ercilasun, A. B. (2016). Başlangıçtan Yirminci Yüzyıla Türk Dili Tarihi. Ankara: Akçağ.

Ercilasun, A. B. (1985). Karahanlı Devri Türk Edebiyatı. A. B. Ercilasun içinde, Büyük Türk Klasikleri 1 (s. 114-179). İstanbul.

Ergüzel, M. M., \& Kirik, E. (2018). Kutadgu Bilig'in Söz Varlığı Ve Kelime Gruplarına Dair. Turkısh Studies , 381-398.

Karaağaç, G. (2013). Dil Bilimi Terimleri Sözlüğü. Ankara: Türk Dil Kurumu.

Lakoff, G., \& Johnson, M. (2015). Metaforlar Hayat, Anlam ve Dil. (G. Y. Demir, Çev.) İstanbul: İthaki.

Nâci, M. (2006). Lûgat-i Nâci. (Ş. Kurt, Çev.) İstanbul: Çağrı.

Sami, Ş. (2007). Kâmûs-ı Türkî . (Ş. Kurt, Çev.) İstanbul: Çağrı.

Sarı, C. (2016). Deyimlerde Aşağı/Yukarı Yönelim Metaforu. Uluslararası Sosyal Araştırmalar Dergisi , 9 (44), 212-216.

Türkçe Sözlük. (2011). Ankara: Türk Dil Kurumu. 